\title{
HLA-A, B, C and DR antigens in young South African blacks with Type 1 (insulin-dependent) diabetes mellitus
}

\author{
M.A. K.Omar ${ }^{1}$, M.G.Hammond ${ }^{2}$ and A.C. Asmal ${ }^{1}$ \\ ${ }^{1}$ Department of Medicine, University of Natal, Durban and ${ }^{2}$ Natal Institute of Immunology, Pinetown, South Africa
}

Summary. The HLA status of South African black Type 1 (insulin-dependent) diabetic patients with age of onset under 35 years was compared with that of healthy black control subjects. HLA-A, B and C antigens were determined in 94 patients and 995 control subjects, while DR typing was carried out on 56 patients and 195 control subjects. There was a significant increase in the frequency of DR4 in patients as compared with control subjects $(p<0.01$; relative risk 3.4$)$. DR3/DR4 heterozygosity was associated with a greater relative risk for developing Type 1 diabetes mellitus (3.7) than the presence of DR3 alone (relative risk 1.6). A significant negative association was observed between the presence of BW42 and Type 1 diabetes in this population sample ( $p<0.04$; relative risk 0.3). A similar trend was observed with regard to DR2, the corrected $p$ value just attaining statistical significance $(p<0.05$; relative risk 0.1$)$.

Key words: HLA-A, B, C DR antigens, Type 1 diabetes, South African blacks, B8/B14, DR4, BW42, DR2, DR3/DR4.
The association between Type 1 (insulin-dependent) diabetes mellitus and the HLA system has been documented in many studies involving different population groups. HLA antigens associated with Type 1 diabetes in White Caucasoids include CW3, CW4, B8, B15, DW3, DW4, DR3 and DR4 [1]. In the Japanese, the disease has been associated with HLA-DYT and BW54 [2, 3] while in South African Indians an association with B8 has been shown [4]. Other studies have shown a relationship with DR3 and DR4 in American blacks [5] and with either B8 or B14, which are cross-reacting antigens, in South African blacks [6]. It is thus evident that there are differences in the specific allelic associations among various ethnic groups.

There is little information on the relationship between Type 1 diabetes mellitus and antigens at the $\mathrm{D}$ locus of the HLA systems in populations other than Caucasoids. Therefore a group of South African blacks with the disease was studied to evaluate the frequencies of HLA-A, B, C and the recently-discovered serologicallydetected DR antigens, which appear to be controlled by genes located at the same locus as the HLA DW antigens [7]

\section{Patients and methods}

All the patients and control subjects were blacks of Zulu descent. HLA-A, B, and C antigens were determined in 94 patients with Type 1 diabetes and 995 control subjects, whilst HLA-DR antigens were de- termined in 56 patients with Type 1 diabetes and 195 controls. Classification of patients as having Type 1 diabetes was based on the revised criteria recommended by the National Diabetes Data Group and the WHO: all had always been dependent on insulin for control of symptoms and prevention of basal ketosis [8,9].

A total of 180 antisera were used in a two-stage microlymphocytotoxicity test to determine HLA-A, -B, and -C specificities. Lymphocytes were isolated on a Ficoll-Hypaque density gradient [10]. HLA-DR specificities were determined in an extended incubation microlymphocytotoxicity test, using T-cell-depleted, B-cell-enriched lymphocytes. The frequency differences between the patients and controls were tested for significance by means of the chi-squared test (without Yates' correction). The resulting probabilities were multiplied by the number of specificities tested in order to determine the corrected value [11]. [12].

Relative risk was calculated according to the method of Woolf

\section{Results}

At the A and C loci there was no difference in the frequency of any of the antigens between patients and control subjects. The lower frequency of $\mathrm{A} 30$ in patients (23.4\% versus $38.4 \%$ ) was not significant after correcting for the number of antigens being tested (Table 1).

The frequency of B14 was increased in patients as compared with control subjects $(12.8 \%$ versus $5.2 \%)$, but this was not significant after correcting the $p$ value (Table 2). Similarly the frequency of B8, although increased in patients $(22.3 \%$ versus $12.8 \%)$, did not attain significance level after correction for the number of an- 
Table 1. Percentage frequencies of HLA-A and -B antigens in patients and control subjects

\begin{tabular}{|c|c|c|c|}
\hline \multirow[t]{2}{*}{ HLA antigen } & \multicolumn{3}{|c|}{ Percentage frequency in } \\
\hline & $\begin{array}{l}\text { Control subjects } \\
(n=995)\end{array}$ & $\begin{array}{l}\text { Diabe } \\
(n=9 .\end{array}$ & $\begin{array}{l}\text { tic patients } \\
\text { 4) }\end{array}$ \\
\hline A1 & 6.5 & 7.5 & \\
\hline $\mathrm{A} 2$ & 21.1 & 25.5 & \\
\hline $\mathrm{A} 3$ & 12.5 & 13.8 & \\
\hline A11 & 0.1 & 0 & \\
\hline AW23 & 17.5 & 24.5 & \\
\hline AW24 & 5.1 & 4.3 & \\
\hline A25 & 14.3 & 8.5 & \\
\hline $\mathrm{A} 26$ & 9.2 & 7.5 & \\
\hline A28 & 20.6 & 23.4 & \\
\hline A29 & 18.1 & 18.1 & \\
\hline $\mathrm{AW} 30^{\mathrm{a}}$ & 38.4 & 23.4 & $\mathrm{rr} 0.5$ \\
\hline AW31 & 7.1 & 8.5 & \\
\hline AW32 & 2.3 & 6.4 & \\
\hline AW33 & 1.6 & 1.1 & \\
\hline One antigen & 25.5 & 27.7 & \\
\hline B5 & 1.3 & 0 & \\
\hline B7 & 19.9 & 18.1 & \\
\hline $\mathrm{B} 8^{\mathrm{b}}$ & 12.8 & 22.3 & \\
\hline B14 & 5.2 & 12.8 & rr 2.7 \\
\hline $\mathrm{B} 8 / \mathrm{B} 14^{\mathrm{c}, \mathrm{d}}$ & 17.7 & 34.0 & $\mathrm{rr} 2.4$ \\
\hline B13 & 4.1 & 5.3 & \\
\hline B15 & 5.0 & 6.4 & \\
\hline B16 & 3.1 & 1.1 & \\
\hline B17 & 38.6 & 36.2 & \\
\hline $\mathrm{B} 18$ & 4.2 & 6.4 & \\
\hline BW21 & 1.2 & 1.1 & \\
\hline BW22 & 0.1 & 0 & \\
\hline B27 & 0.4 & 0 & \\
\hline BW35 & 6.2 & 3.2 & \\
\hline $\mathrm{B} 37$ & 0 & 0 & \\
\hline BW 40 & 0.8 & 0 & \\
\hline BW41 & 2.1 & 9.6 & \\
\hline BW42 & 24.8 & 9.6 & rr 0.3 \\
\hline BW44 & 16.0 & 11.7 & \\
\hline BW45 & 7.7 & 9.6 & \\
\hline BW53 & 1.3 & 1.1 & \\
\hline BW & 19.1 & 14.9 & \\
\hline One Antigen & 36.1 & 30.9 & \\
\hline
\end{tabular}

${ }^{\mathrm{a}} p$ uncorrected $<0.005 ;{ }^{\mathrm{b}} p$ uncorrected $<0.05 ;{ }^{\mathrm{c}} p$ uncorrected $<0.001 ;{ }^{\mathrm{d}} p$ corrected $<0.04 ; \quad \mathrm{rr}=$ relative risk

tigens tested (Table 1). Since HLA-B8 and -B14 form part of a cross-reacting group of antigens, the presence of either of these antigens in the patients was compared with that in the control subjects. The difference is highly significant ( $34 \%$ versus $17.7 \%, p<0.04$, relative risk 2.4 ; Table 1).

There was a lower frequency of HLA-BW42 in patients as compared with control subjects $(9.6 \%$ versus $24.8 \%$, relative risk 0.3 ), the difference being significant even after correction for the number of antigens tested (Table 1).

At the DR locus, Type 1 diabetes mellitus in the black patients was associated with a significant increase in the frequency of DR4 (32.1\% versus $12.3 \%$; relative risk 3.4) even after correcting the $p$ value (Table 2). The frequency of DR2 is lower in patients than in control
Table 2. Percentage frequencies of DR antigen in patients and control subjects

\begin{tabular}{lcrl}
\hline HLA antigen & \multicolumn{2}{c}{ Percentage frequency in } \\
\cline { 2 - 4 } & $\begin{array}{l}\text { Control subjects } \\
(n=195)\end{array}$ & $\begin{array}{c}\text { Diabetic patients } \\
(n=56)\end{array}$ \\
\hline DR1 & 2.6 & 7.1 & \\
DR2 $^{\mathrm{a}}$ & 21.0 & 3.6 & $\mathrm{rr} 0.1$ \\
DR3 & 34.4 & 42.9 & rr 1.3 \\
DR4 & 12.3 & 32.1 & rr 3.4 \\
DR5 & 33.9 & 17.9 & \\
DR6 & 15.9 & 10.7 & \\
DR7 & 12.3 & 23.2 & \\
DR8 & 1.0 & 3.6 & \\
DR9 & 0.5 & 1.8 & \\
DR10 & 2.6 & 1.8 & \\
One antigen & 63.6 & 55.4 & \\
DR3/DR4 & 2.5 & 8.9 & rr 3.7 \\
DR3/any other antigen & 14.3 & 16.2 & \\
DR3/DR blank & 21.4 & 16.2 & \\
DR4/any other antigen & 8.9 & 4.6 & \\
DR4/DR blank & 12.5 & 5.5 & \\
\hline
\end{tabular}

a $p$ corrected $<0.05 ; \quad{ }^{b} p$ corrected $<0.01 ; \quad$ rr relative risk

Table 3 Linkage disequilibrium between HLA-B locus antigens and HLA-DR locus antigens

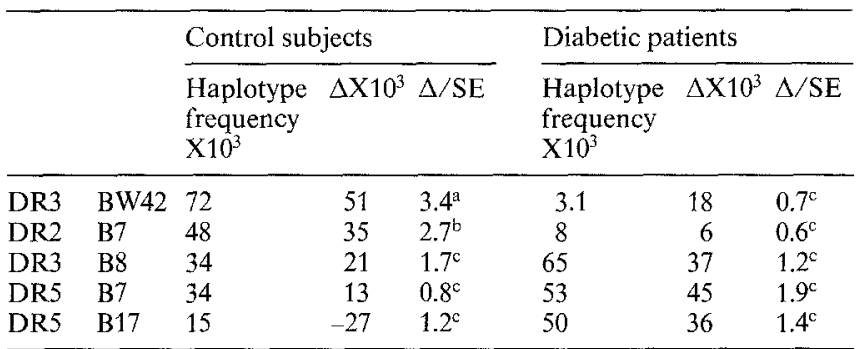

$\triangle / \mathrm{SE}=\mathrm{delta} / \mathrm{standard}$ error.

${ }^{\mathrm{a}} p<0.01 ;{ }^{\mathrm{b}} p<0.05 ;{ }^{\circ}$ not significant

subjects (3.6\% versus $21 \%$ ), the difference just attaining a level of statistical significance after correction for the number of antigens being tested (Table 2). The frequency of DR3 is only slightly higher in patients than in control subjects, there being no significant difference.

HLA-DR3 and DR4 were found together in $8.9 \%$ of patients and in only $2.5 \%$ of control subjects (relative risk 3.7; Table 2). Thus the relative risk of DR3/DR4 heterozygosity was much greater than that for DR3 alone (relative risk 1.3) but only slightly higher than that for DR4 alone (relative risk 3.4).

The occurrence of specific DR antigens together with certain B locus antigens in the same haplotype is shown in Table 3 . Whereas there are significant linkage disequilibra between DR2 and B7 $(\Delta \times 1000=35$, $p<0.05$ and between DR3 and BW42 $(\Delta \times 1000=51$; $p<0.01)$ in control subjects, these phenomena are not seen in the patients $(\Delta \times 1000=18, p>0.05$ and $\Delta \times 1000=6, p>0.05$ respectively; Table 3 ). The HLADR3/B8 haplotype is present in a greater proportion of 
diabetic patients $(6.5 \%)$ than control subjects $(3.4 \%)$ but there is no significant linkage disequilibrium in either group (Table 3 ).

\section{Discussion}

In white Caucasoids two distinct forms of Type 1 diabetes have been recognised and these may be distinguishable on the basis of HLA studies [13]. There is an autoimmune variety which is associated with DR3 and DW3 and less strongly with B8 [13]. The other type has an earlier age of onset and tends to be associated with DR4 and DW4, but less strongly with B15 and CW3 [1].

The present study has demonstrated a significant association between Type 1 diabetes in South African blacks and the presence of HLA-DR4. Such an association has been observed in virtually all the ethnic groups studied thus far [14]: However, an association with DR3 could not be shown among the Zulu patients here, unlike the findings in European Caucasoids [1] and American blacks [5]. It is possible though that such a relationship is still present but masked by the relatively small sample size.

The presence of DR3/DR4 heterozygosity in South African blacks was associated with a much greater susceptibility to Type 1 diabetes than that associated with possession of DR3 alone, but in comparison with DR4 alone, DR3/DR4 did not greatly increase the risk. In white Caucasoids, however, the relative risk associated with possession of both DR3 and DR4 has been found to be much greater than that associated with DR3 alone or DR4 alone [1]. Studies in white Caucasoids have established a negative correlation between Type 1 diabetes and the presence of DR2. Such a trend was also observed among the South African blacks with Type 1 diabetes, the corrected $p$ value being significant at the 0.05 level. In addition, there was a significant negative correlation with BW42 in these patients. It is difficult to gauge the significance of such findings at present, since a decreased frequency of an antigen as opposed to an increased frequency requires a much larger sample size to become evident [15]. The negative correlation between B7 and Type 1 diabetes shown in white Caucasoids [1] was not seen in the black patients described here, nor has it been observed in American blacks [5].

Previously it had been shown that there was a close correlation between Type 1 diabetes in South African blacks of Zulu origin and the presence of either B8 or B14, which are cross-reacting antigens, thus raising the possibility that the same susceptibility gene might be associated with either of these antigens in this population group [6]. The findings in this study, which was extended to involve a larger number of patients, confirmed such a relationship.

The black patients with Type 1 diabetes did not show any increase in the frequencies of CW3, B15, and B18 as has been found in European Caucasoids, nor of
BW54 and B12 as observed in Japanese [1-3]. Studies in American blacks or Nigerians have not shown any significant association at the B locus [15-17]. Patel et al. did find an increased frequency of $B 8$ in the former, but the corrected $p$ value was not significant [18], as has been the case with the black patients reported in this study.

In a study on a small number of Nigerians with Type 1 diabetes none of the patients had A30, whereas it was present in $15 \%$ of the 226 controls [17]. Such a trend has also been observed in this study done on patients who are ethnically related to Africans in the rest of Africa [19].

Linkage disequilibrium between antigens of the $B$ locus and those of the DR locus was observed in this study, but the degree to which this phenomenon occurred was different in control subjects and patients. DR2 and B7 were found together far more frequently in the former. However, the frequency of B7 if present alone does not differ much between patients and control subjects, thereby supporting the well-known conclusion that the relationship between Type 1 diabetes and the HLA system is stronger at the D locus than the B locus [1].

Linkage disequilibrium involving the DR3 - B8 haplotype, which has been a constant finding in white Caucasoids [1], was not a significant finding in the black patients studied here. However, a significant association was seen between DR3 and BW42 in the black control subjects, whilst the frequency of this haplotype was much lower in the patients.

Acknowledgement. This study was supported by South African Medical Research Council.

\section{References}

1. Christy M, Green A, Chuistau B, Kromann H, Nerup J, Platz P, Thomsen M, Ryden LP, Svejgaard A (1979) Studies of the HLA system and insulin-dependent diabetes mellitus. Diabetes Care 2: 209-214

2. Kawa A, Nakazawa M, Sakaguchi S, Nakamuras S, Komo $Y$, Hazeki H, Kanehisa T (1977) HLA system in Japanese patients with diabetes mellitus. Diabetes 26: 591-595

3. Nakao Y, Fukunishi T, Koide M, Akasawa K, Ikeda M, Yahata M, Imura H (1977) HLA antigens in Japanese patients with diabetes mellitus Diabetes 26: 736-739

4. Hammond MG, Asmal AC (1980) HLA and insulin-dependent diabetes in South African Indians. Tissue Antigens 15: 244-248

5. Rodey GE, White N, Fraser TE, Duquesnoy RJ, Santiago JV (1979) HLA - DR specificities among Black Americans with juvenile onset diabetes. N Engl J Med 301: 810-812

6. Hammond MG, Asmal AC, Omar MAK (1980) HLA and insulindependent diabetes in South African Negroes. Diabetologia 19: 101-102

7. Platz P, Thomsen M, Svejgaard A, Cudworth AG, Woodrow JC, Nerup J (1978) More on the genetics of juvenile diabetes. N Engl J Med 301: 810-812

8. National Diabetes Data Group (1979) Classification and diagnosis of diabetes mellitus and other categores of glucose intolerance. Diabetes 28: 1039-1057 
9. WHO Expert Committee Report on Diabetes Mellitus (1980) Second Report. Technical Report Series No 646, World Health Organization, Geneva

10. Boyum A (1967) Separation of leucocytes from blood and bone marrow. Introduction. Scand J Clin Lab Invest 21 (Suppl) 97: 7-108

11. Svejgaard A, Jersild L, Staub-Nielson L, Bodmer WF (1974) HLA antigens and disease. Statistical and genetical considerations. Tissue Antigens 4: 95-105

12. Woolf $B$ (1955) On estimating the relation between blood group and disease. Ann Hum Genet 19: 251-253

13. Nerup J, Andersen OO, Christy M, Platz P, Ryder L, Thomsen M, Svejgaard A (1976) HLA, autoimmunity, virus and the pathogenesis of juvenile diabetes mellitus. Acta Endocrinol (Suppl 1) (Copenh) 83 (Suppl 205): 167-175

14. Svejgaard A, Platz P, Ryder LP (1980) Insulin-dependent diabetes mellitus In: Terasaki PI (ed) Histocompatibility testing 1980. UCLA Tissue Typing Laboratory, Los Angles, pp 653-689

15. Svejgaard A, Hansen M, Jersild C, Platz P, Ryder BP, Staub-Nielson L, Thomsen M (1975) The HLA system. An introductory survey. Monogr Genet 7: 1-100

16. Duquesnoy RJ, MacDonald MJ, Mullins P, Hackbarth SA, Tras- man HS, Levitsy LL (1979) Increased frequency of HLA-DW3 in North American Black patients with juvenile-onset diabetes. Tissue Antigens 13: 369-372

17. Famuyiwa OO, Nwabuebo IE, Abioye AA (1982) Pattern of histocompatibility (HLA) distribution among Nigerian (West African black) diabetics. Diabetes 31: 1119-1122

18. Patel R, Ansari A, Covarrubias (1977) Leucocyte antigens and disease III. Association of HLA-B8 and HLA-BW15 with insulin-dependent diabetes in three different population groups. Metabolism 26: 487-492

19. Tobias PV (1971) The biological invalidity of the term Bantu. S Afr J Sci $67: 517-520$

Received: 5 April 1983

and in revised form: 24 october 1983

Dr. M.A. K. Omar

P.O. Box 17039

Congella 4013

Natal

South Africa 